ÉGYPTE monde arabe

\section{Égypte/Monde arabe}

23 | 1995

Géographies de l'Égypte 2

\title{
Géographies de l'Égypte (II) : Introduction
}

\section{Eric Denis}

\section{OpenEdition}

\section{Journals}

Édition électronique

URL : https://journals.openedition.org/ema/961

DOI : 10.4000/ema.961

ISSN : 2090-7273

\section{Éditeur}

CEDEJ - Centre d'études et de documentation économiques juridiques et sociales

\section{Édition imprimée}

Date de publication : 30 septembre 1995

Pagination : 7-10

ISSN : 1110-5097

\section{Référence électronique}

Eric Denis, «Géographies de l'Égypte (II) : Introduction », Égypte/Monde arabe [En ligne], 23 | 1995, mis en ligne le 08 juillet 2008, consulté le 07 juillet 2022. URL : http://journals.openedition.org/ema/961 ; DOI : https://doi.org/10.4000/ema.961

Ce document a été généré automatiquement le 7 juillet 2022.

Tous droits réservés 


\title{
Géographies de l'Égypte (II) : Introduction
}

\author{
Eric Denis
}

1 La présente livraison d'Égypte/Monde arabe constitue la deuxième partie du dossier "Géographies de l'Égypte », entamé dans le numéro précédent. Dans cette deuxième partie, la question urbaine domine : la ville - essentiellement Le Caire, dont traitent quatre des cinq articles - s'impose à diverses échelles. La centralité du fait urbain celle de la capitale égyptienne en particulier - dans la recherche française s'intéressant à l'Égypte, notamment parce qu'elle n'est pas nouvelle, pourrait nous conduire à survaloriser ce qui n'est qu'une des dimensions territoriales de l'Égypte. Mais la centralité même du phénomène fait que l'urbanisation est finalement de tous les territoires et de tous les champs de recherche. Dans les pages qui suivent, c'est à travers les matériaux les plus divers - enquêtes de terrain, entretiens, données statistiques, articles de presse, plans... - , que sociologues, géographes et urbanistes explorent le champ urbain.

2 C'est en effet en continuant à affiner la mesure de révolution urbaine en Égypte que nous parviendrons à dépasser les catégories ou modes de penser la ville qui, précisément, nous ont conduit à considérer le fait urbain comme une dimension essentielle de l'Égypte contemporaine. Il s'agit notamment de poursuivre l'effort de réflexion sur les rythmes et la spatialisation de la croissance démographique, d'aller au-delà de la notion d'explosion urbaine et d'apporter des mesures toujours plus précises, plus nuancées, plus qualitatives. Le caractère tantôt informel, tantôt planifié de l'espace urbain égyptien et les dynamiques sociales qui accompagnent ces processus sont également des catégories à affiner, à relire sans en gommer les nuances.

Les études rassemblées id tentent de s'écarter des oppositions radicales, même si l'intervention urbaine est toujours justifiée selon des antagonismes du type ville informelle versus ville planifiée ou encore rural versus urbain. Dès lors, comment interpréter cet univers qui se développe à la périphérie des villes d'Égypte et qui représente environ $20 \%$ de la population égyptienne, ou $50 \%$ de la population urbaine? Faut-il parier de «société de l'informel»? Faut-il ajouter une nouvelle 
catégorie aux trois dimensions de l'Égypte - le monde des villes, l'espace rural et les déserts? Est-ce dans ses marges, caractérisées par l'extrême jeunesse de leur population - avec des âges moyens par quartiers atteignant à peine vingt ans, contre dix de plus au centre - que s'invente l'Égypte de demain?

4 Poursuivant un imposant travail d'enquête dans divers quartiers du Caire, Bénédicte Florin nous livre ici le descriptif, au cours des premières années d'habitation, d'un nouveau quartier de logement social qui s'est peuplé massivement à la suite du tremblement de terre d'octobre 1992. L'auteur souligne la diversité des situations sociales et des trajectoires résidentielles des habitants à travers leur perception, leurs modes d'appropriation de l'espace, leur gestion de la distance avec la vieille ville ou avec le centre, dont la plupart sont issus. Elle montre par là même comment se construit une nouvelle identité en rapport avec l'éloignement. En effet, nous dit-elle, « les va-et-vient matériels et symboliques entre l'espace de provenance et l'espace de résidence, les imbrications entre les lieux ne permettent pas de parier de deux systèmes territoriaux distincts: tout se passe comme si l'appropriation d'un nouvel espace de vie ou la constitution d'une nouvelle territorialité se faisait par rapport au quartier précédent. »

5 Agnès Deboulet souligne, dans un travail de formalisation d'une étude de terrain effectuée au sud du Caire, que «la dichotomie légal/illégal, de même que celle qui oppose habitat majoritaire et habitat vernaculaire, oppose deux réalités qui puisent souvent l'une dans l'autre ». Elle relève par ailleurs que le constat de l'uniformité du Caire fondé sur l'étude morphologique "dispense trop souvent de concevoir la diversité urbaine ». Par là même, elle nous introduit à toutes les subtilités de l'accès au sol et au logement dans un quartier soumis à l'« invasion foncière », dégageant un ensemble de pratiques et d'usages «allant de soi » qui s'imposent en normes et interrogent la notion d'illégalité.

6 Si l'on s'intéresse à l'évolution de la distribution des groupes sociaux entre 1976 et 1986 dans l'ensemble de l'agglomération du Caire (article d'Eric Denis), il apparaît clairement que toutes les franges de la société n'ont pas les mêmes capacités à se maintenir au cœur de la ville et que la mixité sociale du centre, si souvent soulignée, se délite. En revanche, la croissance des périphéries est plus complexe qu'il n'y paraît. Les marges non planifiées se développent comme une forme de résistance de la mixité sociale, de la proximité, et s'opposent en cela aux nouveaux quartiers planifiés à l'homogénéité sociale affichée. Avec l'analyse de la centralité, la réflexion sur la mixité semble constituer un des points d'accroche des recherches urbaines conduites en Égypte, un de ceux qui font débat et ouvrent de nombreuses perspectives.

7 L'action publique ne semble pas avoir pris la mesure des différentes évolutions en cours, même si des revirements intéressants se font jour dans le domaine des régularisations de quartiers informels. Les travaux de Sabine Jossifort et de Frédérique Bruyas semblent d'ailleurs indiquer que l'intervention urbanistique a fait - et fait toujours - appel à une «boîte à outils " standard du type schéma directeur, ville nouvelle, zoning, logement social ou périphérique dans la lignée du mouvement moderniste, sans se soucier des dynamiques qui, au quotidien, contribuent à une distorsion croissante entre la ville légale et l'agglomération urbaine.

8 Frédérique Bruyas souligne combien les utopies réformistes des urbanistes ne sont souvent que des coups de crayon instrumentalisés par les politiques et les lobbies économiques, et par l'urgence. La reconstruction de Port-Saïd a été conçue comme la 
fondation d'une nouvelle société, à l'image de bien des chantiers urbains qui ont suivi la fin d'un conflit (par exemple, ceux de l'après-guerre en Europe). Le témoignage de l'architecte-urbaniste Yahya al-Zayni, acteur de la reconstruction de Port-Saïd, autour duquel est construit l'article de F. Bruyas, montre qu'en fin de compte le pragmatisme remporte. Le projet s'incline devant les réalités. Une réelle réforme urbaine exige une réforme sociale, plus qu'une intervention conforme aux canons de l'urbanisme.

Mais dans l'immédiat, comme le souligne Sabine Jossifort, les exigences de l'ajustement structurel conduisent plutôt à abandonner aux industriels et aux promoteurs le devenir des new settlements et des villes nouvelles qui s'élèvent aujourd'hui autour du Caire. Sur ces vastes trames viabilisées à grand frais par l'état égyptien, la priorité va désormais au développement des résidences de luxe. Faute de pouvoir réformer la ville, on offre à ceux qui en ont les moyens des possibilités de s'en distancer, amplifiant encore les clivages sociaux. Les frontières se déplacent, se recomposent là où l'on ne les attendait peut-être pas: il était plutôt de bon ton d'imaginer qu'une certaine "sarcellite" guettait les villes nouvelles.

On pourra encore dans la présente livraison, avec un texte du géographe égyptien Gamâl Hamdân sur Le Caire (partie "Traduire »), mettre en perspective les articles rassemblés ici et disposer d'une vision plus structurelle. On y distinguera les présupposés ayant servi à justifier la mise en œuvre du projet de réforme moderniste du cadre urbain (migration, ruralisation, explosion démographique.,.).

11 Ces contributions, jalons d'une recherche en cours, montrent que l'observation de l'urbanisation réserve encore bien des surprises, tant dans ses nouvelles tendances qu'à travers les retours et relectures que peuvent mener les uns ou les autres sur les dynamiques antérieures. La présence conjointe, au Caire, de doctorants d'Urbama, de l'Orstom et du Cedej intéressés par les questions urbaines et d'un programme soutenu par le Pirville (CNRS) à l'Observatoire urbain du Caire contemporain permet, à travers les échanges, que progresse notre connaissance des villes d'Égypte, et témoigne d'une volonté de participer au débat général sur la ville.

\section{AUTEUR}

ERIC DENIS

Cedej-CNRS 